\title{
MIRACLES ARE NOT VIOLATIONS OF THE LAWS OF NATURE BECAUSE THE LAWS DO NOT ENTAIL REGULARITIES
}

\section{DANIEL VON WACHTER}

\author{
IAP Liechtenstein
}

\begin{abstract}
Some have tried to make miracles compatible with the laws of nature by re-defining them as something other than interventions. By contrast, this article argues that although miracles are divine interventions, they are not violations of the laws of nature. Miracles are also not exceptions to the laws, nor do the laws not apply to them. The laws never have exceptions; they never are violated or suspended, are probably necessary and unchangeable, and apply also to divine interventions. We need to reconsider not miracles but laws. The main claim of this article is that laws of nature do not entail regularities, and therefore that miracles do not violate the laws. We need a new theory of the laws of nature: the tendency theory.
\end{abstract}

\section{THE IDEA OF MIRACLES AS VIOLATIONS OF THE LAWS}

The claim that miracles, or divine interventions in general, are impossible has been exceedingly influential. This claim was used by atheists in order to criticise theism, and led theologians to deny the occurrence of miracles and to re-interpret miracles as something other than divine interventions. Further, it moved many to assume that, although there is a God, in order to create the animals he never intervened, perhaps not even in order to create the first animal. This claim is also connected to the definition of miracles as 'violations of the laws of nature', which led some to believe that miracles are impossible and others to believe that, although miracles are possible, they are exceptions to the laws and they are the only exceptions. The arrival of the idea of probabilistic laws and processes through quantum mechanics made some authors think that 
these revisions finally show that there is room for miracles in the causal order of the world - assuming that if the laws were not probabilistic, then there would be no room for miracles. ${ }^{1}$

Let me illustrate this attitude with some quotations. Spinoza (16321677) claimed,

Nothing, then, happens in nature which is in contradiction with its universal laws. [... She] preserves a fixed and immutable course. [...] A miracle, whether contrary to nature or above nature, is a sheer absurdity; and therefore that by a miracle in Holy Writ we are to understand nothing more than a natural phenomenon which surpasses, or is believed to surpass, human powers of comprehension. (Tractatus, ch. 6)

Similarly Voltaire (1694-1778),

A miracle is the violation of mathematical, divine, immutable, eternal laws. By the very exposition itself, a miracle is a contradiction in terms: a law cannot at the same time be immutable and violated. (1764, Philosophical Dictionary, 'Miracles', quoted in McGrew 2014)

Since Friedrich Schleiermacher (1768-1834) this principle was widely accepted as axiomatic in German protestant theology. Ernst Troeltsch in 1898 thus declared the following 'principle of correlation' to be a principle of theology,

$[\mathrm{N}]$ o change can occur at one point without changes occurring before and after at other points, so that all events stand in a continuous, correlative interconnection and must necessarily constitute a single flow in which each and all hang together, and every event stands in relation to others. ${ }^{2}$

The New Testament scholar Rudolf Bultmann expressed it thus:

The idea of a miracle as a divine intervention has become impossible for us today, because we understand all that happens in nature as

${ }^{1}$ A different way to argue for the impossibility of miracles would be to posit the 'principle of causal closure', which Kim (1998: 40) formulates as follows: 'If you pick any physical event and trace out its causal ancestry or posterity, that will never take you outside the physical domain. That is, no causal chain will ever cross the boundary between the physical and the nonphysical.' In Wachter 2006 I object to this principle that it is not a result of physics (cf. Plantinga 2011: 89) and that it can be defended only by providing evidence against the existence of immaterial objects, and a modal version of the principle cannot be defended at all. See also Lowe 2000.

${ }^{2}$ Troeltsch (1898: 733). For a discussion of this principle, see Plantinga 1998. 
law-governed. Thus we understand a miracle as a violation of the lawgoverned connection between all that happens in nature, and this idea we cannot entertain today any more. (Bultmann 1933: 84f., my transl.)

Later, Anglo-Saxon theologians adopted the claim, e.g. Langdon Gilkey,

$[C]$ ontemporary theology does not expect, nor does it speak of, wondrous divine events on the surface of natural and historical life. The causal nexus in space and time which the Enlightenment science and philosophy introduced into the Western mind [...] is also assumed by modern theologians and scholars; since they participate in the modern world of science both intellectually and existentially, they can scarcely do anything else. (Gilkey 1961: 31)

Even today many follow this approach. For example, Nancey Murphy (1995: 343) states, 'We object to interventionist accounts of divine action because it seems unreasonable that God should violate the laws he has established.' Murphy is part of the 'Divine Action Project' (DAP), co-sponsored by the Vatican Observatory and the Center for Theology and the Natural Sciences in Berkeley. ${ }^{3}$ The leader of this project is Robert Russell, who gave his view the telling name: 'NIODA' - NonInterventionist Objective Divine Action. Such authors do not just want to say that there are also divine actions which are not interventions. Instead, they want to affirm the existence of God and of divine action without accepting the existence of any divine interventions.

\section{DEFINING MIRACLE AND INTERVENTION}

In this article I shall argue that there is no reason for this aversion to interventions since this aversion is based on a misconception of the laws of nature. Usually by a miracle we mean a divine intervention into the ordinary course of material things, an intervention that functions as a sign for someone. ${ }^{4}$ We would not, therefore, usually call God's creating of an animal by intervention a 'miracle', if such creation took place before there were humans to whom this event would also function as a sign.

${ }^{3}$ For discussions of the DAP, see Plantinga 2011, $\$ 4.2$ and Wildman 2004.

${ }^{4}$ For a thorough defence of a similar definition see Larmer 2014, ch. 2. This is a simplification of the ordinary usage of the word 'miracle' because we also call it a miracle if the apostle Peter heals a lame man, as in Acts 3:7. This too is an intervention into the ordinary course of material things, but through a human action performed in virtue of extraordinary human powers. 
In this article I am concerned with the principle of divine interventions in the broad sense. Regardless of the issue of signification I define an intervention as that which those authors whom I quoted above want to avoid: a divine intervention is an event that is brought about by God in an action, has no preceding cause, and is incompatible with, and occurs instead of, an event towards which a causal process was directed.

More generally, such an event that is brought about by an agent in an action and has no preceding cause I call a choice-event. ${ }^{6}$ So a divine intervention is a choice-event of God that interferes with a causal process. In all this I am assuming the existence of causal processes that have a direction. The idea of an intervention implies further that a process can be stopped, which is what the believers in the 'causal nexus' want to deny.

\section{REGULARITIES OF SUCCESSION}

The quotations above presuppose a certain view of the causal structure of the world - the 'causal nexus'. Its main element is David Hume's idea that laws entail regularities of the form 'All events of type $\mathrm{x}$ are followed by events of type y'. I call this 'the regularity view'. It is further assumed that every event is an instance of a regularity of succession (ROS). Every event is, or is a part of, an event of a type $\mathrm{x}$ such that all events of type $\mathrm{x}$ are always followed by an event of type $\mathrm{y}$. We can call this the 'causal nexus' view. It excludes all divine interventions, for example miracles, because an intervention is an event that is not an instance of a ROS. It is an event of type $\mathrm{z}$ following an event of type $\mathrm{x}$ while on other occasions events of type $\mathrm{x}$ are followed by, and cause (in some sense), events of type y.

Although Hume's view that laws are nothing but ROSs is generally rejected today, the most popular theories of laws of nature today still assume that laws entail ROSs, i.e. that if a certain law of nature exists or is true, then there is a certain ROS. David Lewis's (1973: 73) 'best system analysis' claims that a law is a description of a ROS which is an axiom or a theorem in the simplest description of all events. The ArmstrongDretske-Tooley theory (Armstrong 1983; 1997) claims that a law is

\footnotetext{
${ }^{5}$ In Wachter 2011 I have argued that events brought about by God have no preceding cause in the divine mind. If one rejects this, then one has to add here that a divine intervention has no preceding cause in the natural world.

${ }^{6}$ For more on this see Wachter 2003 and Wachter 2009, ch. 7.
} 
a universal that relates property universals. If a law holds between $\mathrm{F}$ and $G$, then all Fs are $G$, or rather whenever some thing is $F$, afterwards it will turn G. ${ }^{7}$ Brian Ellis (2001), in his 'scientific essentialism', agrees with the others that there are ROSs and that the laws entail ROSs; he just objects to the Humeans (including David Lewis) that they fail to give an explanation of the existence of the ROSs, and to David Armstrong that he gives the wrong explanation (Ellis 2010: 134). Similarly Stephen Mumford assumes that there are ROSs that are described by law statements and that the ROSs are explained in terms of properties and de re necessities, but he holds that there are 'no laws in nature, in the metaphysically real sense of laws' (Mumford 2004: 23) (non-realism about laws).

This wide agreement on the regularity view is a serious challenge to the theist. If the laws entailed ROSs, then it would be correct to call miracles 'violations of the laws of nature' and either to take them to be impossible or, as Richard Swinburne (2003: 19) does, to take them to be 'non-repeatable exceptions' to the laws. But I shall argue that these theories are following the wrong track and that laws do not entail ROSs.

\section{LOOKING FOR REGULARITIES}

Let us look for regularities of succession that are entailed by the laws of nature. Consider the law of gravity,

$$
F=G \frac{m_{1} m_{2}}{d^{2}} .
$$

Is there a regularity which is entailed by this equation? The first candidate is that any two bodies with mass m mutually attract and accelerate towards one another at the following rate,

$$
a=G \frac{m}{d^{2}}
$$

But they do not, because often, in fact always, there are more things influencing their movement. For example, if there is a third body with

\footnotetext{
${ }^{7}$ For a discussion of the possibility of divine action given this view, see Fales 2010: 3-4.
} 
mass $\mathrm{m}$, that mirrors the state of the first body with respect to the second body, but along a vector of separation that is diametrically opposite to that of the first body with respect to the second body, then the second body will not accelerate at all. There also can be other kinds of influences on the body's movement, for example electro-magnetic forces. Such influences are possible because there can be (and typically will be) a superposition of forces, in other words, forces are additive and can be counteracted.

Perhaps we find a regularity by considering a larger state of affairs, including the other things that influence the body. But a list of things or events does not entail or necessitate that there are no other things or events. Whatever events (at the time in question) you include in $\mathrm{x}$, sometimes an $\mathrm{x}$-event will be followed by a y-event, sometimes by some other type of event. The law of gravity describes what follows an $\mathrm{x}$-event when there are no other forces and no other things at work. But as there can be other forces and other things, the law of gravity entails no ROS, however big an event you consider. Even if $U$ is a complete description of the universe (at the time in question), the law of gravity does not say that a U-state will always be followed by a certain y-state, because $U$ does not entail that there are no things besides U. Only if you add the clause 'and there is nothing else' or 'there is nothing else acting', does the statement make a claim about what will happen. Hence no matter how many additional factors are included in the first event, up to and including the influences of everything else in the universe, regularities still cannot be rescued without including this additional clause, even if only implicitly. For example, one can derive from the law that 'Whenever there are two bodies with mass $\mathrm{m}$, separated by distance $\mathrm{d}$, and no further things are influencing their motion, they accelerate towards one another following an inverse square law, but that is not a ROS.

Perhaps the law of gravity does not entail a ROS but the totality of the laws does. This way we take into account not only gravitational forces but also electromagnetic and all other forces. One could assume that material or spatial things exert no other forces than those described by the laws of nature. It is a plausible but not trivial assumption that all forces exerted by material things on one another can be known by knowing their masses, mutual separations and other characteristics, such as electric charges. We could then assume that the totality of the laws of nature entails, for each description of a material state of affairs, a complete description of the forces exerted by it. 
But still we do not obtain a ROS, for two reasons. First, because, as explained above, no list of things excludes the existence of further things, for example other material things, angels, or God. Secondly, because being the result of a causal process, as defined above, is not the only way an event can come about. An event can be the result of a causal process and thus be caused by preceding events, or it can be a choice-event, so that it has no preceding cause but is brought about by an agent. The agent can be immaterial or (a materialist may claim) material. In any case, the totality of the laws of nature also entails no ROSs, but only conditional prediction statements of the form: If an event is of type $x$ and no further things are affecting what follows, then an event of type $y$ will follow. The laws also entail general causal statements of the form: Events of type $x$ cause events of type $y$ if nothing prevents them from causing.

The prediction statements entailed by laws leave open not only the possibility of intervention by material things but also by God. If an $\mathrm{x}$-event once causes a y-event, then in other cases of $\mathrm{x}$-events the y-event may be prevented by other things, e.g. other material things or God. Some might want to say that the laws allow for interventions only by forces exerted by material things and thus that they entail prediction statements of the form 'If an event is of type $\mathrm{x}$ and no other material thing is exerting a force on what follows, then an event of type y will follow. But that is false; the laws do not entail this. The laws would entail this only if they entailed that there are no immaterial things. Even if there were no God, there would be no way to derive this fact from the laws of nature. If someone were to add it to a law statement, then the resulting statement would not be justified by the observations. If there are no immaterial things and no choice-events, then the prediction statements that are calculated on the basis of all the laws and all material things all happen to be true even without the clause 'no further things are acting.' But without that clause they are not entailed by the laws but only by the laws plus the metaphysical assumption that there are no immaterial things and no choice-events.

The laws already do not entail ROSs because of the possibility of intervention by forces exerted by material things. But there can also be interventions by agents through choice-events. Interventions can therefore occur through: non-probabilistic material processes; or probabilistic material processes; or free rational or non-rational actions by embodied agents; or free rational or non-rational actions by nonembodied created agents; or free rational actions by God. 


\section{WHY DO THE LAWS NOT ENTAIL REGULARITIES OF SUCCESSION?}

Why did so many believe that there are ROSs and that laws of nature entail them? This belief is plausible on the assumption that causal processes are unstoppable. This assumption was stated, and declared to be a priori and certain, by Thomas Hobbes,

Whatsoever effects are hereafter to be produced, shall have a necessary cause; so that all the effects that have been, or shall be produced, have their necessity in things antecedent. $(1655$, De corpore, $\$ 9)$

This is determinism as it is understood today: every event is necessitated by preceding events. If someone believes this, then he may well believe that all events of type $x$ necessitate events of type $y$, and that the laws entail ROSs which describe what causes and necessitates what and thus how processes develop. Especially in the $19^{\text {th }}$ century belief in determinism was widespread, ${ }^{8}$ which is why quantum mechanics in the 1920 s met with disbelief and was such a shock.

But there are no such processes. ${ }^{9}$ A rolling billiard ball can be stopped by a ball, a cat, a man, a demon, or God. Non-probabilistic processes cannot stop by chance; they are heading in one direction. But they can be stopped, or deflected, by a thing that is strong enough. Deterministic causes and processes in the usual sense, implying the impossibility of being stopped, do not and cannot exist. A more useful sense would be: A deterministic process is one that can stop only if something stops it. Processes need not be probabilistic in order to be stoppable.

It is illustrative to see how Hobbes' argument for determinism in De corpore $\$ 9$ fails. He argued as follows: If an event occurred, then its cause was complete, otherwise it would not have occurred. 'An entire cause is always sufficient for the production of its effect.' 'It follows also from hence, that in whatsoever instant the cause is entire, in the same instant the effect is produced. For if it be not produced, something is still wanting, which is requisite for the production of it.' Therefore, 'whatsoever effects are hereafter to be produced, shall have a necessary cause; so that all the effects that have been, or shall be produced, have their necessity in things antecedent.'

${ }^{8}$ For example, Kant's principle of causation was widely accepted: 'Every event is determined by a cause according to constant laws.' (Kant, Prolegomena, $\$ 15$ )

${ }^{9}$ For a defence of this claim see Wachter 2012. 
As John Bramhall (Bramhall 1655: 172) was quick to point out, Hobbes' mistake was to derive from 'Every event has a sufficient cause' (everything was there that was needed for the causing) that 'Every event has a necessitating preceding cause.' The rolling of billiard ball A before time $t$ caused the rolling of billiard ball $B$ after $t$. The cause was complete and in this sense sufficient to push B, but the cause did not necessitate B's rolling, because something could have prevented B's rolling, for example B's being glued to the table, another ball, a cat, or a demon. Moreover, non-probabilistic causes do not necessitate their effects, and in addition, non-probabilistic processes can be stopped.

We can and should even question whether there are ROSs at all. In a very small world with just two perfectly similar spheres, the answer might be 'yes'. They might perpetually collide and move away from each other. But consider a middle-sized event like two billiard balls, A and B, colliding in a larger universe like ours. It may happen on other occasions that these two balls or other similar balls move in the same way. But they will not always move in this way, because sometimes there are other balls hitting them, or a magnet or a cat affects them. Or a demon or God. Considering a less than exact description of the objects and the event does not help either: neither 'Balls with some mass moving in way w' nor 'Two bodies with masses $\mathrm{m}$ and separation $\mathrm{d}$, with accelerations that follow an inverse square law', yields a ROS. If you consider larger events, such as one consisting of 17 bodies, then you might find some ROSs - but only if there are very few instances of that event type. For event types of which there are many instances, it is probable that they will not all cause events of the same type. God could intervene sometimes in order to bring it about that for some event types, A and B, A-events are always followed by B-events. But without such interventions it is very improbable that there are ROSs of event types of which there are many instances, because the more instances of the first event type there are, the more probable it is that on some occasion something will bring about a different outcome than in those cases in which nothing else is affecting the outcome. This problem is exacerbated by the chaotic behaviour of complex systems, by which even tiny perturbations are rapidly magnified. Besides these considerations, even if there were some ROSs, it would be impossible to acquire a justified belief about them because one can never know whether there will be an exception in the future. 


\section{CETERIS PARIBUS LAWS}

The contemporary debate about ceteris paribus laws also highlights ways in which the laws of nature do not entail ROSs. Many philosophers hold that some or all laws of nature require ceteris paribus clauses, for the reasons that I have given above for my claim that laws entail only prediction statements that contain a 'and no further things are acting' clause. Such philosophers want to hold the view that laws entail prediction statements of the form 'All events of type $\mathrm{x}$ that are under the same conditions are followed by events of type y' ${ }^{10}$

But John Earman and John T. Roberts (1999; 2002) have argued that the fundamental laws do not contain ceteris paribus clauses, and if a formula does contain ceteris paribus clauses, then it is not a fundamental law but part of a 'work-in-progress-theory',

If laws are needed for some purpose, then we maintain that only laws will do, and if 'ceteris paribus laws' are the only things on offer, then what is needed is better science, and no amount of logical analysis on the part of philosophers will render the 'ceteris paribus laws' capable of doing the job of laws. (Earman and Roberts 1999: 466)

While they hold that laws do not require ceteris paribus clauses, they say that applications of a theory require what Carl Hempel called 'provisos'. As an example of an application of a theory, Hempel considers a description of the motion of two bodies that are 'subject to no influences from within or from outside the system that would affect their motions' (Hempel 1988: 158). Discussing the proviso required for this, Hempel touches the issue of miracles:

The proviso must [...] imply the absence [...] of electric, magnetic, and frictional forces; of radiation pressure; and of any telekinetic, angelic, or diabolic influences. (Hempel 1988: 158, also quoted in Earman and Roberts 1999: 444)

So Hempel recognises the possibility of divine interventions, and the need to exclude such interventions by fiat. To achieve this objective, he proposes the proviso, 'the total force acting on each of the two bodies equals the gravitational force exerted upon it by the other body; and the latter force is determined by the law of gravitation.' The expression 'total force' is supposed to exclude telekinetic, angelic, diabolic, etc., influences. As a diabolic influence would be an action and, in my view, not a 'force'

${ }^{10}$ For a comprehensive investigation of ceteris paribus laws see Schrenk 2007. 
in the strict, Newtonian sense, Hempel should say instead that 'nothing besides the gravitational force exerted by the two bodies is affecting their motion. But the point is clear: While laws of nature do not require ceteris paribus clauses or 'provisos', 'applications of theories' do.

We can find the reason why Earman and Roberts hold, against most other authors, that the fundamental laws do not require ceteris paribus clauses if we examine what they write in the light of our question whether laws entail regularities of succession. Earman and Roberts do not address this question explicitly, but what they say implies that laws do not entail ROSs. In a footnote, they take the law of gravitation 'as asserting' this position, using the following words:

(Regardless of what other forces may be acting) any two massive bodies exert a gravitational force on one another that is directly proportional to the product of their masses and inversely proportional to the square of the distance between them. (Earman and Roberts 1999: 473, footnote 14)

Their objections to Nancy Cartwright's claim, which she expressed already in the title of her book How the Laws of Physics Lie (1983), that the laws lie because bodies do not move in the way which the laws describe, point in the same direction:

Universal Gravity cannot misrepresent the motion of a body, because it says nothing specific about such temporal behaviour. Only differential equations of evolution type - which might be derivable from UG together with other considerations - can be integrated to describe the temporal motion of a body or system of bodies. UG cannot be so integrated. Thus, it cannot misrepresent temporal motion. [...] [T]here is more packed into this differential equation than just laws. What is really wrong with the differential equation is that it was derived under the assumption that nothing carried a net charge, a false non-nomic assumption. (Earman, Roberts and Smith 2002: 286f.)

Although Earman and Roberts in other articles (2005a; 2005b) defend 'Humean Supervenience', which probably means that forces are reducible to what happens when and where or to something else that is not a force, ${ }^{11}$ this interpretation is in fact leading towards my theory, which

${ }^{11}$ Earman and Roberts (2005a: 1) defend Humean Supervenience as the claim that 'what is a law of nature, and what not, supervenes on the Humean base'. By this they mean that 'two possible worlds cannot differ on what is a law of nature unless they also differ on the Humean base. They propose that 'the Humean base at a given world is the 
I shall state below, that laws of nature do not entail ROSs and do not say how bodies move, but say, rather, that there are forces of certain kinds in situations of certain kinds.

\section{LAWS VERSUS EQUATIONS OF MOTION}

What I have discussed in the previous section draws attention to an important clarification: We need to distinguish between laws of nature on the one hand, such as the law of gravitation and, on the other hand, equations of motion ('applications of theories') understood as either specific predictions of what will happen in a particular situation or understood as general statements about how systems of a certain type will develop. A law of nature, in my view, is true always and without conditions or provisos; it applies also to cases in which there are things acting that the law does not take into account and in which, therefore, the conditions are not the same ('ceteris paribus') than in ideal cases in which there are no factors that the law does not describe. By contrast, an equation of motion is true only if a 'no further things are affecting the movement of the bodies' clause is included.

In the title of her book 'How The Laws of Physics Lie', Nancy Cartwright (1983) shows that she means by 'laws of physics' equations of motion or predictions, because the title means that often bodies do not move as the laws predict. I reply that this conclusion is to be avoided by two steps: First, laws of nature, such as the law of gravitation, say nothing about what happens, just about what forces there are. Second, equations of motion, understood as predictions, require not just ceteris paribus but 'no further things are acting' clauses - and with these they do not lie.

Miracles violate neither laws nor equations of motion. Miracles do not violate the laws, because laws do not entail ROSs. Miracles do not

set of non-nomic facts at that world that can be the output of a reliable, spatiotemporally finite observation or measurement procedure'. (Earman and Roberts 2005a: 17) Does this mean that forces are part of the Humean base? In my view they can be observed or measured, but Earman and Roberts write that their version of HS captures the idea that the distinction between the initial and boundary conditions and the laws from which the differential equations are derived is not a 'metaphysical distinction between two fundamentally different kinds of facts'. (2005a: 15) Thus they mean by the Humean base 'the set of all facts that could serve as initial or boundary conditions'. (2005a: 16) That indicates that Earman and Roberts think that forces are reducible to what happens when and where or to something else that is not a force, because irreducible forces are not the kind of thing that is referred to as initial conditions. 
violate equations of motion because these require the 'no further things are acting' clause. Equations of motion without the clause are false because there can be further things acting so that things do not move according to the equation. The clause is needed not just because of the possibility of divine interventions but also because of the possibility of a process being interfered with by another material process.

\section{THE TENDENCY THEORY OF LAWS OF NATURE}

Thus far I have defended the negative claim that laws of nature do not entail ROSs. In order to bring out why miracles do not violate the laws, I want to say also positively what a law of nature is. We should take our cue from real examples from physics, for example the law of gravitation ${ }^{12}$ rather than from pseudo-examples like 'All swans are white' or 'Metal expands when heated. This law of mechanics says that there are forces of certain types in situations of certain types.

What is a force? ${ }^{13}$ Let me present two thought exercises designed to help us to understand, or describe, what a force is. First, let us consider how we feel or observe forces. You can exert a force with your finger on a ball. You can feel a force that is exerted by a ball on your hand. You can imagine or believe that a ball is exerting a force on a table on which it is lying or on a ball which it hits. The object on which the force is exerted then is heading in a certain direction, it is pressed or pushed to move in that direction - even if it is impeded from moving. Likewise, the body that exerts the force is heading in a certain direction.

Second, more generally, consider a universe - for simplicity's sake one without living beings - at some time t. How will it carry on after $t$ ? There are many possibilities. There could be after $t$ any one of many possible universes, for example one with just five stones or one like ours was in 1517. But we do not believe that all these possibilities are equally likely. We believe that at each time the universe is heading in a certain direction. There is a tendency in the universe to carry on in a certain way, rather than in one of the many other possible ways. By using the word 'tendency' here, I do not wish to imply any randomness or chance. Let us

12 The physicist Richard Feynman, in his book The Character of Physical Law (Feynman 1965), also uses the law of gravitation for investigating what a law of nature is.

${ }^{13}$ For a defence of the reality of Newtonian forces, resultant and component, see Massin 2009, $\$ 2$. 
put aside all such ideas for now and consider the universe as if there was no chance and as if Newton's laws were the ultimate ones.

In order to grasp what this 'heading in a certain direction' is, we need to contemplate and consider the things in themselves attentively. Conceptual analysis will not provide us with insights. The heading in a certain direction has to do with, but does not consist in, how the universe or a part of it will carry on after the time under consideration. The bodies have a tendency to move in a certain way or direction. I prefer to say: There is a tendency (in the universe) at time $t$ towards the bodies after $t$ moving in a certain way, i.e. towards the bodies being at certain positions at certain later times. Equivalently we can say: 'There is a tendency at $t$ that after $\mathrm{t}$ the bodies will be at certain positions at certain times. ${ }^{14}$ That there is a force applying to a body at $t$ means that there is, in this sense, a tendency in the universe at time $t$ towards the bodies being at certain positions at certain times after t. More generally, there is a tendency at time $t$ that at certain times after $t$ certain things will be the case, matter will be a certain way.

A force is a tendency in this sense. It is a tendency concerning the positions or movements of bodies. But there are other tendencies, concerning other changes or developments. Therefore my theory of laws does not say that a law says that there are forces of certain kinds in situations of certain kinds, but that a law of nature says that there are tendencies of certain kinds in situations of certain kinds. J. S. Mill already hinted at this in 1843 when he wrote: 'All laws of causation, in consequence of their liability to be counteracted, require to be stated in words affirmative of tendencies only, and not of actual results.' (Mill 1843: book III, ch. 10, $\$ 5$ )

A tendency depends on a state of affairs. Not everything there is at $t$ is relevant for the obtaining of the tendency. If two planets attract each other, then a cat on a distant planet is irrelevant for that tendency. Likewise, while the mass of and the distance between the two planets are relevant, their temperature is not. Therefore, tendencies are not based on substances, as a philosopher who claims that laws are about 'dispositions' ${ }^{15}$ or 'powers' might say, but on states of affairs: complexes of properties at certain places or things at certain times. In order to refer

\footnotetext{
${ }^{14}$ I have developed this notion of a tendency and this theory of laws in more detail in Wachter 2009, ch. 5 .

${ }^{15}$ For example Lowe 2006, $₫ 8.6$ and Göcke 2015 hold that laws are about the dispositional behaviour of natural kinds.
} 
to a certain state of affairs in this sense, and thus in order to refer to the basis of a tendency, one needs to specify which properties at which thing or where at which time one means. ${ }^{16}$ So there is a state of affairs, $S$, consisting of certain properties at certain bodies or places at a certain time $\mathrm{t}$, which is the basis of the tendency. It is impossible ${ }^{17}$ that $\mathrm{S}$ exists while the tendency does not. It is also impossible that the tendency exists without its basis.

If a state of affairs of type $S$ is the basis of a tendency of type $T$, then other states of affairs of type $S$ are also the bases of tendencies of type $T$. I assume that that is necessarily so and that there is no causal explanation for this. If two states of affairs are bases of dissimilar tendencies, then they are also in themselves dissimilar. But I do not need to explore this possibility here. The core of the tendency theory of laws of nature is that laws describe what kinds of states of affairs are the bases of what kinds of tendencies.

If nothing counteracts a (non-probabilistic) tendency, then things carry on following the tendency; the tendency is realised. But there can always be another tendency or an agent that counteracts a tendency, impeding its realisation. I assume that if $\mathrm{S}$ is the basis of tendency $\mathrm{T}$ at time $t$ towards a certain state of affairs at a certain later time $t_{2}$, then $T$ is also a tendency towards a certain states of affairs at all times between $t$ and $t_{2}$.

Not only changes and a body's acceleration, but also constant movement is a matter of tendency. If there is no force acting on a body, there is still a tendency that the body will be at certain positions at certain times. I assume further that a thing's persisting unchangingly through time is a matter of tendency. It consists in there being a tendency towards there being a thing with certain properties at certain positions at certain times. But not every state of affairs or event occurs through the realisation of a tendency. It can also be a choice-event, i.e. occur in an action and have no preceding cause.

\footnotetext{
${ }^{16}$ I favour David Armstrong's 1997 conception of a state of affairs, but not much turns on this here. Even the difference that is usually made between states of affairs and events is not relevant here. My point is that one refers to the basis of a tendency by specifying property, thing or place, and time.

${ }^{17}$ I always mean impossibility simpliciter, which comes closest to what usually is called 'metaphysical' impossibility. So I recognise only one kind of modality and do not use the usual distinction between 'logical', 'natural' and 'metaphysical' impossibility. Laws are, probably, necessary in the simple, strict sense. See Wachter 2009, ch. 3.
} 
Is not Newton's second law, establishing a proportional relationship between force and acceleration, a counter example to the claim that laws state that there are tendencies of certain kinds in situations of certain kinds? Does not that law describe not tendencies but the actual movement of bodies? If we wanted to interpret the law in this way, then we would have to add a 'nothing else is acting' clause. But it is more adequate to say that the law describes the movement towards which the body on which the force acts is heading - regardless of whether the body will actually move in this way. Without Newton's second law we could not calculate exactly what tendency there is when two planets attract each other. We could calculate the force, but this would only entail the direction but not the velocity of the acceleration towards which the tendency is directed. Newton's second law together with the laws that describe that there are forces of certain kinds in situations of certain kinds is a description of the tendencies there are. So Newton's second law is also a part of the description of tendencies.

We now see a further flaw of the ceteris paribus approach. Usually laws are assumed to entail ROSs whose instances are all the instances of the law. Ceteris paribus clauses are used in order to express that the law does not apply to those cases in which the conditions are not the same. But it is false that the law does not apply to those cases. Even if the gravitational force exerted on a body by another body does not lead to acceleration, because an electromagnetic force or an animal impedes it, the gravitational force is still there and the law of gravitation applies.

\section{BACK TO MIRACLES}

Now we can draw the conclusions concerning miracles. Are miracles violations of the laws? They would be if the laws said or entailed that no miracles occur. Consider the case of Peter walking on the water. God prevents Peter from sinking into the water; he holds him. What do the laws say about that? They say that there are certain tendencies, in this case that there is a gravitational force pulling him down. Is the miracle contrary to what the laws say? Only if God abolishes the gravitational force. Does he? Even if God could do that (which perhaps even an omnipotent person, rightly understood, cannot do), there is no reason to take such drastic measures; God can hold Peter without abolishing 
any tendencies. He sustains Peter, the water, and the tendencies, and by holding Peter, God counteracts the tendency towards Peter sinking into the water. Alternatively, God could act on the water holding the water molecules so that Peter does not sink. God would not thereby violate any laws, because he would not abolish any tendencies concerning the water. A miracle is no violation of any law of nature because the laws say that there are certain tendencies, and God does not abolish any tendencies; they are all there. ${ }^{18}$

Can God change the laws? If the laws are necessary, as I think, then even an omnipotent or maximally powerful person cannot change them. Of course, God could have created a universe made of different stuff, and he could change the stuff in our universe so that bodies attract each other less. Then different laws would describe the existing tendencies. In some possible cases only the constants would be different. In some cases it might look as if the laws changed, but in fact it is not the laws that changed, but the kinds of things described by the laws. The laws have changed only in the sense that different laws now describe the tendencies that exist. It is impossible that two exactly similar states of affairs are the bases of different tendencies. That is what I mean by the hypothesis that the laws are necessary.

If God intervenes by moving a body, does he thereby produce a force? If one defines 'force' so that any acceleration is the result of a corresponding force, then the answer is 'yes'. But this response is not the most appropriate one (as argued by Massin 2009: 557f.), because, for example, a gravitational force on a body is dissimilar from God moving a body directly, a tendency is different from God bringing about a state of affairs directly. A tendency is based on a state of affairs, but God's acting is not. A tendency can be counteracted and overriden by another tendency, but God's acting cannot. A tendency at $t_{1}$ towards state of affairs $S$ at $t_{2}$ is also a tendency towards states of affairs at times between $t_{1}$ and $\mathrm{t}_{2}$ and at later times. Nothing corresponds to this temporal ordering in God's acting. A tendency is the universe's heading in a certain direction, but God's acting is God's bringing about a state of affairs in an action as a choice-event. Therefore, when God intervenes, he does not bring about a tendency, e.g. a force, but he brings about a state of affairs directly as a choice-event.

${ }^{18}$ For another, slightly different defence of the view that miracles are not violations of the laws, see Larmer 2014, ch. 2. 
One possible view about the relationships between miracles and laws is that the laws do not apply to miracles. The laws describe what material things cause and that therefore, if an immaterial agent causes a material event, the laws say nothing about that case. This is C. S. Lewis's view, and it is expressed well by Jan Cover,

... [B] elieving in events having supernatural causes, needn't saddle one with believing that there are false laws of nature, laws having exceptions. Miracles are so to speak 'gaps' in nature, occurrences having causes about which laws of nature are simply silent. The laws are true, but simply don't speak to events caused by divine intervention. ${ }^{19}$

Along with this view, which we can call the not-apply view or the silence view, one can say that miracles do not violate the laws, because on this view the laws do not say that there are no miracles. I object to this view, however, since I claim that the laws also apply to miracles and are not silent about them insofar as they describe tendencies, and such tendencies remain, even though God counteracts. ${ }^{20}$

Richard Swinburne accepts the idea that miracles are violations of the laws but interprets it in the sense of a miracle being 'a non-repeatable exception to a law of nature' (Swinburne 2004: 279). A miracle is a violation of a law in that it is a $\mathrm{z}$-event following an $\mathrm{x}$-event while according to the law $\mathrm{x}$-events are followed by $\mathrm{y}$-events. But because $\mathrm{x}$-events are not always followed by $\mathrm{z}$-events, the law is still a law, the law statement is still true. To this view too I object that a miracle is in no sense a violation of a law because laws apply also to miracles, insofar as they describe tendencies. Further, I object to the idea that miracles are the only exceptions to the laws. The laws apply to miracles no less than they apply to cases where material objects counteract the tendencies. A material object's counteraction is as much a counteraction as a divine counteraction is, and an intervention by a material object or process is as much an intervention as a divine intervention is. Likewise, animals and humans can, by acting, counteract tendencies and intervene in processes. ${ }^{21}$

${ }^{19}$ Quoted by Larmer 2014, ch. 2. Similarly Plantinga (2011: 78): 'according to Newton and classical mechanics, natural laws describe how the world works when, or provided that the world is a closed (isolated) system, subject to no outside causal influence.' Also C. S. Lewis in his book Miracles holds such a view.

${ }^{20}$ For the principle of energy conservation, the not-apply view is correct. See Larmer 2014, ch. 2 and Collins 2008.

${ }^{21}$ For a discussion of Swinburne's view, see Larmer 2014, ch. 5. 
Swinburne holds that because miracles are violations of the laws of nature, they are in themselves improbable. The fact that if E occurred, it would have been a miracle is in itself 'evidence against its occurrence',

This is because the past phenomena which make it probable that $\mathrm{L}$ is a law of nature make it probable that it holds almost universally and so that on the occasion in question, things conformed to L. (Swinburne 1992: 118)

In my view this is not so. It is true that today, at least in the West, ${ }^{22}$ miracles are somewhat improbable. One needs stronger evidence to justify the belief that God raised your friend's daughter from the dead than for the belief that she is dead. But the reason for this difference of evidence is not that miracles are violations of the laws, nor that rising from the dead would be a miracle. Rather, the reason is that today, I assume, God does not very often raise people from the dead or intervene very visibly in other ways. The low frequency of miracles today lowers the prior probability of miracles, but the mere fact that they are miracles does not. Imagine that God were to perform miracles very often. Then you would need less evidence in order to justify the belief that God raised your friend's daughter from the dead.

\section{CONCLUSION}

The question of miracle led us to question the general view of the laws and of the causal structure of the world, according to which laws entail regularities of succession and even every event is an instance of a regularity of succession. Against this view I have argued that laws do not entail regularities of succession but describe tendencies, e.g. Newtonian forces. Miracles are not violations of the laws because in the case of a miracle the tendencies that the laws describe remain.

This claim is strikingly at variance with all current prominent theories of laws of nature, given that such theories assume that laws do entail ROSs. But I suggest that my claim is not contrary to our intuitions and observations. Nothing in the law of gravitation, for example, indicates that it entails regularities of succession. Rather, the most straightforward interpretation is that there are certain forces in certain situations. We

${ }^{22}$ According to Keener 2011, part 3, there seem to be more credible reports of miracles in other parts of the world. 
also do not observe or experience ROSs. The idea that there are ROSs (other than regularities with just a few instances) is implausible because we know that for each event in other cases of events of that type there may be something which causes a different outcome. Events of one type often cause and are therefore followed by events of a certain other type, otherwise we could not build cars and computers, but the idea that events of one type are always followed by events of a certain other type is a claim of a different order.

Belief in ROSs is most probably based on a more basic commitment, namely to determinism or to empiricism. In my view, belief in determinism prevents philosophers from recognising that processes can be stopped and makes them believe that it is possible that an event necessitates a later event, or even that all events are necessitated by preceding events. As one can then believe that events of type $\mathrm{x}$ necessitate events of type $y$, that paves the way for belief in regularities of succession. Belief in empiricism prevents philosophers from recognising forces and other tendencies and leads them to believe instead in regularities of succession, although, ironically, we do not observe them. Once we put aside these two doctrines, then we recognise a third alternative besides Hobbesian deterministic processes and probabilistic processes: processes that have a unique direction from which they cannot deviate by chance, without a cause, but from which they can be caused to deviate. Then we can accept that laws of nature describe the direction of processes, or, more precisely, tendencies.

Some may even be motivated in part to assume the existence of ROSs because that allows a quick argument against miracles (and against free will). But whether and which miracles have occurred can be discovered only by considering the evidence, not a priori. The theist as well as the atheist have the tasks of examining, for example, the historical evidence for the resurrection of Jesus in detail. ${ }^{23}$ Investigating the laws of nature does nothing to determine whether miracles occurred.

Some theists are worried that there is no room for miracles, for example Keith Ward claims that 'there must be gaps in physical causality if God is ever to do anything' (Ward 2000: 903). Some therefore put their

${ }^{23}$ The evidence for the resurrection of Jesus is investigated, for example, by Swinburne 2003, T. McGrew and L. McGrew 2012, Craig 2000, Habermas and Licona 2004, and Wright 2003. Swinburne points out that not only the detailed historical evidence, such as the reports of witnesses, but also several kinds of background evidence need to be considered. 
hope in quantum mechanics, speculating that God acts by determining the outcome of probabilistic processes on the quantum level. ${ }^{24}$ There is no need for all this. Even if the Newtonian laws, which are as deterministic as any are, were the ultimate laws, miracles would be perfectly possible. Hence we are at fully at liberty to consider the only question that really matters, and to which this paper serves as a prelude, namely whether and which miracles have, in fact, occurred..$^{25}$

\section{BIBLIOGRAPHY}

Armstrong, David M. 1983. What Is a Law of Nature? (Cambridge: Cambridge University Press)

Armstrong, David M. 1997. A World of States of Affairs (Cambridge: Cambridge University Press)

Bramhall, John. 1655. 'A Defence of True Liberty from Antecedent and Extrinsical Necessity', in Works vol. 4. (Oxford: John Henry Parker, 1844), pp. 23-196

Bultmann, Rudolf. 1933. 'Zur Frage des Wunders', in Neues Testament und christ-liche Existenz (Tübingen: Mohr Siebeck), pp. 84-98

Cartwright, Nancy. 1983. How the Laws of Physics Lie (New York: Oxford University Press)

Collins, Robin. 2008. 'Modern Physics and the Energy-Conservation Objection to Mind-Body Dualism', American Philosophical Quarterly, 45.1: 31-42

Craig, William Lane. 2000. The Son Rises: Historical Evidence for the Resurrection of Jesus (Eugene, Oregon: Wipf \& Stock)

Earman, John and John T. Roberts. 1999. "Ceteris Paribus", There Is No Problem of Provisos', Synthese, 118.3: 439-478

Earman, John and John T. Roberts. 2005a. 'Contact with the Nomic: A Challenge for Deniers of Humean Supervenience about Laws of Nature, Part I: Humean Supervenience', Philosophy and Phenomenological Research, 71: 1-22

Earman, John and John T. Roberts. 2005b. 'Contact with the Nomic: A Challenge for Deniers of Humean Superveni-ence About Laws of Nature Part II: The Epistemological Argument for Humean Supervenience, Philosophy and Phenomenological Research, 71.2: 253-286

${ }^{24}$ For example Russell 2009 and also Plantinga’s Divine Collapse Causation (Plantinga 2011: 116-121). For objections to Plantinga see Wachter (2014: 56f).

${ }^{25}$ I am grateful to Joseph Jedwab, Benedikt Göcke, Olivier Massin, Ralf Bergmann and especially Andrew Pinsent for helpful comments on this article. 
Earman, John, John T. Roberts, and Sheldon Smith. 2002. 'Ceteris Paribus Lost', Erkenntnis, 57.3: 281-301

Ellis, Brian. 2001. Scientific Essentialism (Cambridge: Cambridge University Press)

Ellis, Brian. 2010. 'Causal Powers and Categorical Properties', in The Metaphysics of Powers: Their Grounding and Their Manifestations, ed. by A. Marmodoro (Dordrecht: Routledge), pp. 133-142

Fales, Evan. 2010. Divine Intervention: Metaphysical and Epistemological Puzzles (London: Routledge)

Feynman, Richard. 1965. The Character of Physical Law (New York: The Modern Li-brary)

Gilkey, Langdon. 1961. 'Cosmology, Ontology, and the Travail of Biblical Language', in God's Activity in the World: The Contemporary Problem, ed. by Owen C. Thomas (Chico, California: Scholars Press), pp. 194-205

Göcke, Benedikt. 2015. 'Did God do it? Metaphysical Models and Theological Hermeneutics', International Journal for Philosophy of Religion, forthcoming Habermas, Gary R. and Michael R. Licona. 2004. The Case for the Resurrection of Je-sus (Grand Rapids, MI: Kregel Publications)

Hempel, Carl Gustav. 1988. 'Provisos: A Problem Concerning the Inverential Function of Scientific Laws', Erkenntnis, 28.2: 147-164

Keener, Craig. 2011. Miracles: The Credibility of the New Testament Accounts, 2 vols. (Grand Rapids, MI: Baker)

Kim, Jaegwon. 1998. Mind in a Physical World: An Essay on the Mind-Body Problem and Mental Causation (Cambridge, Mass.: MIT Press)

Larmer, Robert A. 2014. The Legitimacy of Miracle (Lanham: Lexington Books) Lewis, David K. 1973. Counterfactuals (Cambridge: Harvard University Press)

Lowe, E. J. 2000. 'Causal Closure Principles and Emergentism', Philosophy, 75: $571-585$

Lowe, E. J. 2006. The Four-Category Ontology: A Metaphysical Foundation for Natural Science (Oxford: Clarendon Press)

Massin, Olivier. 2009. 'The Metaphysics of Forces', Dialectica, 63.4: 555-589

McGrew, Timothy. 2014. 'Miracles', The Stanford Encyclopedia of Philosophy (Winter 2014 Edition), ed. by E. N. Zalta. Available at: http://plato.stanford. edu/entries/miracles/ [accessed 05/11/2015]

McGrew, Timothy and Lydia McGrew. 2012. 'The Argument from Miracles: A Cumulative Case for the Resurrection of Jesus of Nazareth', in The Blackwell Companion to Natural Theology, ed. by W. L. Craig and J. P. Moreland (Oxford: Wiley-Blackwell), pp. 539-662

Mill, John Stuart. 1843. A System of Logic Ratiocinative and Inductive (New York: Harper, 1882)

Mumford, Stephen. 2004. Laws in Nature (London: Routledge) 
Murphy, Nancey. 1995. 'Divine Action in the Natural Order: Buridan's Ass and Schrödinger's Cat', in Chaos and Complexity: Scientific Perspectives on Divine Action, ed. by R. J. Russell, N. Murphy and A. R. Peacocke (Vatican Observatory Publications), pp. 325-357

Plantinga, Alvin. 1998. 'Two (Or More) Kinds of Scripture Scholarship', Modern Theology, 14.2: 243-278

Plantinga, Alvin. 2011. Where the Conflict Really Lies: Science, Religion, and Naturalism (Oxford: Oxford University Press)

Russell, Robert John. 2009. 'Divine Action and Quantum Mechanics', in Philosophy, Science, and Divine Action, ed. by F. LeRon Shults, Nancey Murphy and Robert J. Russell (Boston: Koninklijke Brill), pp. 351-404

Schrenk, Markus. 2007. The Metaphysics of Ceteris Paribus Laws (Frankfurt: Ontos Verlag)

Spinoza, Benedict de. 1670. Tractatus Theologico-Politicus, trans by Robert Willis (London: Trübner \& Co., 1862). Available at: <https://en.wikisource.org/ wiki/Theologico-Political_Treatise_1862/Chapter_6> [accessed 02/12/2015]

Swinburne, Richard. 1992. Revelation: From Metaphor to Analogy (Oxford: Clarendon Press)

Swinburne, Richard. 2003. The Resurrection of God Incarnate (Oxford: Clarendon)

Swinburne, Richard. 2004. The Existence of God (second edition) (Oxford: Clarendon)

Troeltsch, Ernst. 1898. 'On the Historical and Dogmatic Methods in Theology', in Gesammelte Schriften, vol. 2., trans. by H. J. Forstman (Tübingen:P J. C. B. Mohr, 1913), pp. 728-753

Wachter, Daniel von. 2003. 'Free Agents as Cause', in On Human Persons, ed. by K. Petrus (Frankfurt: Ontos Verlag), pp. 183-194

Wachter, Daniel von. 2006. 'Why the Argument from Causal Closure against the Existence of Immaterial Things is Bad', in Science - A Challenge to Philosophy? Ed. by H. J. Koskinen, R. Vilkko and S. Philström (Frankfurt/M.: Peter Lang), pp. 113-124

Wachter, Daniel von. 2009. Die kausale Struktur der Welt. Eine philosophische Untersuchung über Verursachung, Naturgesetze, freie Handlungen, Möglichkeit und Gottes kausale Rolle in der Welt (Freiburg: Alber)

Wachter, Daniel von. 2011. 'Do the Results of Divine Actions Have Preceding Causes?', European Journal for Philosophy of Religion, 3: 347-367

Wachter, Daniel von. 2012. 'Kein Gehirnereignis kann ein späteres festlegen', Zeitschrift für philosophische Forschung, 66: 393-408

Wachter, Daniel von. 2014. 'Defending Design Arguments Against Plantinga', Philosophia Reformata, 79: 54-65 
Ward, Keith. 2000. 'Divine Action in the World of Physics: Response to Nicholas Saunders', Zygon, 35: 901-906

Wildman, Wesley J. 2004. 'The Divine Action Project, 1988-2003', Theology and Science, 2: 31-75

Wright, N. T. 2003. The Resurrection of the Son of God (Minneapolis: Fortress Press) 